УДК 821.161 .1

\title{
О.Б. Заславский
}

\section{ЕЩЕ РАЗ О ДВОЙНОЙ СТРУКТУРЕ «ВЫСТРЕЛА» А.С. ПУШКИНА}

Выявлен ряд элементов структуры «Выстрела», ранее не замеченных. В основном они представлены набором оппозиций или реализуют непосредственно мотив удвоения. Этот мотив связан с противостоянием противников и особенностями аномальной дуэли, в том числе ситуацией «пуля в пулю». В результате жизнь Сильвио предстает как единый сюжет; его детали выражены на языке оружия, которое было им применено либо значимым образом осталось без применения. В частности, это относится к правилам карточной игры в банк, в которой участвовал Сильвио. Художественно значимыми в произведении оказываются противостояние клинка и пули, жара и холода, огня и воды, утра и вечера. Эти категории также относятся к графу и рассказчику. Указано на ряд скрытых элементов в кратком упоминании о гибели Сильвио.

Ключевые слова: мотив, художественное время, дуальные противопоставления.

DOI: $10.35634 / 2412-9534-2021-31-2-276-282$

\section{Введение}

Повести «Выстрел» свойственна богатая и разветвленная художественная структура, в которой особую роль играют отношения симметрии. Еще Д. Благой отметил и подробно описал симметричные построения в этой повести [2, с. 223-240]. При этом ключевой структурный элемент - это удвоение; соответственно, особую роль приобретают дуальные противопоставления. В основном Благой сосредоточился на их роли в композиции ${ }^{1}$. Между тем, это проявляет себя не только в композиции, но на самых разных уровнях текста, в результате чего система структурных оппозиций создает двойную структуру произведения в целом. Эти особенности уже подробно исследовались нами в предыдущей работе [3]. Вместе с тем, часть важных дуальных (со)противопоставлений между элементами структуры осталась невыявленной. То, что внешне выглядит как бытовое описание (например, относящееся к распорядку дня персонажей) или описание природных факторов, при ближайшем рассмотрении обнаруживает структурную упорядоченность, за которой просматривается лейтмотив повести - стрельба и ее роль в судьбе главных героев.

Ниже речь в основном пойдет о четырех разных группах элементов такого рода. Во-первых, это - карточная игра. Недавно нами уже было показано, что в особенностях карточной игры с участием «сумасброда» $\mathrm{P}^{* * *}$ проявил себя скрытый мотив удвоения, столь важный в истории дуэли Сильвио [5, с. 88-90]. Но дело не только в этом конкретном эпизоде: как мы увидим, сами по себе правила игры в банк реализуют в повести мотив удвоения.

Во-вторых, мы хотим подчеркнуть наличие противопоставления между разными видами оружия - огнестрельным и холодным.

В-третьих, упомянутое выше противопоставление двух видов оружия - это частный случай противопоставления между жаром и холодом. В свою очередь, как мы увидим, все это метонимически затрагивает экзистенциальные коллизии в жизни главных героев. Сюда также можно добавить противопоставление воды и огня, причем вода и сама по себе оказывается существенным фактором в судьбе героя.

В-четвертых, в повести проявляет себя противопоставление утра (света) и вечера (темноты), что в свою очередь приводит к значимости суточного (природного) цикла, в том числе отрицающего дискретные дуальные противопоставления.

Мы увидим, что присутствие всех этих факторов - как культурных, так и природных (и которые не являются независимыми, а взаимодействуют между собой в общем смысловом поле) приводит к наличию в произведении «неочевидных смысловых структур» [7], и попытаемся описать их свойства.

\footnotetext{
${ }^{1}$ Такая симметрия проявляет себя и на психологическом уровне, раскрывая внутреннюю эволюцию героев, что подробно обсуждалось в работе Шоу [14].
} 


\section{Игра в банк}

Сквозь все произведение лейтмотивно проходят мотивы стрельбы, выстрела, проявляя себя довольно неожиданным образом или оставаясь в (полу)скрытом виде. В частности, это рассматривалось в нашей предыдущей работе [4]. В другой нашей работе было указано на структурные соответствия между характером «удвоенной дуэли» и ее уменьшенным отражением в эпизоде конфликта с офицером $\mathrm{P}^{* * *}[5$, с. 88-90]. При этом воспроизводилась ситуация «пуля в пулю». Теперь мы хотим обратить внимание, что не только эти особенности одного эпизода, но и сам факт игры в карты у Сильвио имеет отношение к лейтмотиву дуэли.

Сильвио метал банк. При этом выигрыш / проигрыш банкомета и понтера наступал тогда, когда карта, которую показывает банкомет, совпадала с картой понтера. Но это - не что иное как удвоение, аналог ситуации «пуля в пулю». Одновременно, такое удвоение придает содержательность звукосмысловым переплетениям КАРТа - КАРТина, на которые указал С. Давыдов [13, с. 66 - 67].

Еще один важный момент с рассматриваемой точки зрения состоит в том, что Сильвио долго не соглашался на карточный «поединок»: «Долго он отказывался, ибо никогда почти не играл» [9, с. 66]. Это напоминает, как граф (причем дважды) пытался отнекиваться от новых условий поединка, предложенных Сильвио (который предлагал графу выстрелить), но в конце концов согласился. Это соотносится как с первой (уже состоявшейся) дуэлью, так и ее повтором. В последнем случае Сильвио предвосхищает действия своего противника, а эпизод приобретает профетическую функцию [11].

\section{Клинок и пуля}

Сильвио служил ранее в гусарах. Их культурно значимым военным атрибутом считается сабля $^{2}$. Когда произошел инцидент на балу, приведший к дуэли между Сильвио и графом, первый жест в столкновении был связан именно с этим оружием: оба противника «бросились к саблям». Но сабле не довелось показать себя в деле. Далее она вообще нейтрализуется: на место дуэли граф шел с мундиром, надетым на саблю. Гусарский мундир, надетый на главное оружие гусара, в сочетании с поеданием черешен дает картину беззаботности и беззлобности - в противоположность Сильвио, который в преддверии выстрела злобствует («волнение злобы во мне было столь сильно, что я не понадеялся на верность руки и, чтобы дать себе время остыть, уступал ему первый выстрел» [9, с. 69]). Уже эти примеры указывают на противопоставление между огнестрельным и холодным оружием.

В эпизоде ссоры офицер Р*** швыряет в Сильвио шандал. Это - подставка для свечей, которых, судя по описанию ситуации, в нем не было. То есть горячий компонент в данном случае значимо отсутствовал, и в этом смысле шандал выступил в буквальной роли холодного оружия. Кроме того, с холодным оружием его здесь роднит и то, что применение «оружия» можно заметить (в отличие от мгновенного и не замечаемого глазом перемещения пули).

В рассматриваемом контексте и ряд, казалось бы, чисто бытовых деталей получает дополнительную смысловую нагруженность, связанную с намеками на холодное оружие. Так, постоянные обеды у Сильвио предполагают коллективное использование ножей и вилок: вместо военной службы в гусарском полку, от которой Сильвио отказался, получилось мирное бытовое использование острых предметов в компании военных.

Финал повести - сражение под Скулянами, где (по слухам) гибнет Сильвио. Там, как известно (и, в частности, описано в «Кирджали»), турки не могли стрелять в греков, так как иначе могли попасть в русских, стоявших на другом берегу Прута (от возможных нарушений этого запрета в реальном бою отвлекаемся). Но греки не были связаны никаким соглашением и вполне могли стрелять в турок. Архангельский пишет, что «стрелок Сильвио погиб не от выстрела и не от выстрелов погибли его последние враги» [1]. Первое утверждение безусловно правильно. С учетом запрета на стрельбу со стороны турок, действительно приходится считать, что погиб Сильвио именно от холодного оружия - клинка или копья. Однако второе утверждение ни на чем не основано. Запрета грекам стрелять в турок не было. И нет никаких оснований считать, что Сильвио упустил шанс на свой последний выстрел (до этого в повести несколько раз была показана ситуация, когда Сильвио уклонялся от выстрела).

\footnotetext{
${ }^{2}$ Это, разумеется, не противоречит тому, что в практике реального боя гусарами применялось и огнестрельное оружие.
} 
Таким образом, противостояние клинка и пистолета в судьбе Сильвио в конечном счете закончилось тем, что победил клинок. Главное оружие Сильвио, с которым был связан смысл его жизни, проиграло. С другой стороны, вполне возможно (и даже скорее всего) он все же сумел хотя бы перед гибелью сделать наконец свой выстрел. Это могло быть последним жестом стрелка, выстрел которого наконец приобрел какой-то смысл. Однако достоверной информации о такой жизненной самореализации Сильвио не осталось.

В результате жизнь Сильвио выстраивается как целый сюжет, связанный с оружием. Начиная со службы в гусарском полку, она сопровождается событиями, связанными с холодным оружием метонимически выраженным признаком гусара. Причем проявления этого оружия оказываются неблагоприятными для Сильвио. Он так и не пускает саблю в ход против своего противника (графа), от которого получил пощечину. Становится жертвой нападения при ссоре за карточным столом. Лишает сам себя возможности реализовать свое предназначение гусара, «отсидевшись» во время Отечественной войны [5, с. 92-95]. И, наконец, погибает от холодного оружия на войне.

Сильвио как бы изменяет сабле - своему оружию гусара, неразрывно связанному с его несостоявшейся судьбой. И это оружие ему мстит, оставляя его в роли неудачника. Но и реализовать свою приверженность к огнестрельному оружию и фантастическую способность к меткой стрельбе ему тоже не удается, причем по причине его собственного отказа от участия в войне или выстрела на дуэли. Лишь в самый последний момент он, возможно, стреляет во врага, но про это нет никаких достоверных сведений.

\section{Жар и холод}

Противопоставление огнестрельного и холодного оружия - это частный случай противопоставления жара и холода, которое проявляет себя на протяжении всего произведения. Стрельба на дуэли сама по себе уже подразумевает «огонь». В первых же строках упоминались занятия офицеров в местечке, в том числе «вечером пунш и карты». Но пунш неразрывно связан с наличием пламени (ср. «и пунша пламень голубой» в «Медном всаднике»). Сильвио ушел в отставку и покинул сферу, где присутствовал огонь реальный; в частности, напомним, что он сознательно пропустил Отечественную войну [5]. В результате вместо огня на поле боя получился лишь огонь при попойках в среде его знакомых военных. Сильвио говорит о графе, который стал искать его «дружества»: «я принял его холодно». Про офицера, запустившего в Сильвио шандал, говорится: «Офицер, разгоряченный вином». Выше уже упоминались отсутствующие свечи в шандале. Когда граф рассказывает о визите Сильвио и упоминает свой выстрел, «лицо его горело как огонь; графиня была бледнее своего платка» [9, с. 74]. Когда граф входит в свой кабинет, то Сильвио стоит возле камина, т.е. возле огня. «Он медлил - он спросил огня. Подали свечи» $[9, \text { с. } 73]^{3}$.

Помимо сочетания жара и холода встречается сочетание огня (света) и тьмы. Про реакцию Сильвио на выходку офицера Р*** говорится: «побледнев от злости, и с сверкающими глазами» [9, с. 66]. Сильвио читает известие о графе: «Пробегая письмо, глаза его сверкали» [9, с. 67]. Во время прощального разговора: «Мрачная бледность, сверкающие глаза и густой дым», «стал набивать выгоревшую свою трубку» [9, с. 68]. О первой дуэли Сильвио говорит: «Он вспыхнул и дал мне пощечину», «в ту же ночь поехали мы драться» $[9, \text { с. 69 }]^{4}$. Однако дуэль, разумеется, совершается не в темноте, а утром: «Весеннее солнце взошло, и жар уже наспевал» [9, с. 69]. Сильвио сообщает офицерам: «еду сегодня в ночь» $[9$, с. 67$]$.

\footnotetext{
${ }^{3}$ О других аспектах мотивов жара (связанных с адом), см. [6, с. 120].

${ }^{4}$ Недавно появилась статья, где говорится о наличии целого ряда намеренных ошибок в «Выстреле» [8]. В качестве одного из примеров авторы указывают, что эта фраза «прямо противоречит идущему вослед подробному описанию дуэли. Она состоялась не в ту же ночь, но утром, а до того требовалось договориться с секундантами, которые должны были оповестить соперников и об условиях поединка, и о «назначенном месте»». С нашей точки зрения, то обстоятельство, что противники поехали драться в ночь, не дождавшись рассвета, просто выдает их нетерпение; при этом, естественно, дуэль в любом случае началась бы только после наступления рассвета. Никаких оснований видеть здесь нарративную ошибку мы не находим. Также, нет никакого неправдоподобия в том, что противники в такой ситуации успели договориться с секундантами - не говоря уже о том, что, судя по аномальному отложенному выстрелу, эти секунданты были терпимыми к отклонению от традиционных правил дуэли.
} 


\section{Огонь и вода}

В произведении значимо еще одно дуальное соотношение, одним из членов которого является «огонь». Это - противопоставление между огнем и водой, где в качестве «воды» может выступать и вино (так что в тексте возникает мотив жидкости). По поводу несостоявшейся дуэли, т. е. отсутствия огня, сказано: «честь его была замарана и не омыта по его собственной вине» [9, с. 67]. Сюда также можно отнести неоднократное упоминание мотивов пьянства. В деревне, куда был вынужден удалиться рассказчик, и где жили горькие пьяницы (сам рассказчик опасался превратиться в одного из них), пьянство явственно связано с бессмыслицей существования. Однако такое упоминание деревенского пьянства бросает тень и на осмысленность «шумной и беззаботной жизни» военного, существенным образом связанной с попойками. В гостях у графа он вспоминает про ротмистра, который объясняет промах по бутылке: «знать у тебя, брат, рука не подымается на бутылку» [9, с. 72]. Навык стрельбы (офицерского качества) оказывается бессильным перед атрибутом пьянства.

На обедах у Сильвио «шампанское лилось притом рекою» [9, с. 65]. Здесь упоминается река как условный образ мирной обстановки. Однако конец жизни Сильвио был связан с реальной рекой в боевых условиях, поскольку в сражении при Скулянах этеристы были притиснуты к берегу Прута. При этом вновь проявил себя мотив жертвы. Дело в том, что у этеристов была возможность отойти на русский берег, однако они предпочли принять последний бой на турецкой стороне - ср. с тем, как Сильвио подставляет себя под пулю противника на дуэли. Тут еще следует учесть, что река - это традиционный мифопоэтический символ, связанный с разделением на мир жизни и мир смерти.

\section{Начало и конец}

Обычно категория времени в «Выстреле» рассматривается для установления его внутренней хронологии [12, с. 220-221]. Этот вопрос действительно очень важен и ведет к содержательным следствиям (например, с ним связан вопрос о том, как Сильвио провел время, когда в стране шла Отечественная война [5]). Однако в тексте «Выстрела» важны не только даты и соотношения между ними, но и свойства художественного времени сами по себе.

Как это было подчеркнуто Благим, «первая дуэльная встреча между Сильвио и графом происходит ранним утром, вторая - вечером, «в темноте» [2, с. 232]. Благой это связывает с противопоставлением героев, где графу (доминирующему в первом случае) соответствует солнечный свет, а Сильвио (доминирующему во втором) - тьма ${ }^{5}$. Мы же хотим обратить внимание на другой аспект (интерпретации Благого не противоречащий): поскольку дуэльная история инициирована Сильвио, то движение от утра к вечеру может пониматься как ее развертывание от начала к концу. Внутри же 1-й дуэли время как бы течет наоборот (аномалия самой дуэли дублируется аномалией ее временного развертывания): дуэльная история начинается ночью (противники поехали «в ту же ночь»), но, разумеется, сама дуэль происходит утром. Традиционная метафора, которая уподобляет человеческую жизнь дню, указывает на то, что жизнь Сильвио с завершением дуэли исчерпывает свой смысл: относительно скоро (вероятно, в течение года [10, с. 409]) он погибает под Скулянами.

На линейное развертывание сюжета от «утра» к «вечеру» как метафоры жизни накладывается циклический, повторяющийся процесс, связанный с суточным циклом. Впервые характеристика времени суток появляется в эпиграфе к повести «Вечер на бивуаке». Далее упоминание суточного цикла возникает в описании жизни военных в местечке ***: «Утром ученье, манеж; обед у полкового командира или в жидовском трактире; вечером пунш и карты» [9, с. 65]. Причем, из-за упоминания пунша, здесь вечернее (темное) время суток как бы озаряется пламенем пунша. На временной цикл накладывается пространственный: в манеже совершается круговое движение, не имеющее ни начала, ни конца. После выходки офицера $\mathrm{P} * * *$ «На другой день в манеже мы спрашивали уже, жив ли еще бедный поручик» [9, с. 66]. Здесь сочетаются вопрос об обрыве линейного процесса (жизни) во времени и круговое движение.

Если в начале повести круговое движение связано с нормой, повторяющимся процессом, то во 2-й части - с аномалией. Граф вспоминает о себе: «Голова моя шла кругом» [9, с. 74]. Здесь речь шла

\footnotetext{
${ }^{5}$ Противопоставление света и темноты почти нейтрализуется в жизни рассказчика в деревне: «До обеда кое-как еще дотягивал я время, толкуя со старостой, разъезжая по работам или обходя новые заведения; но коль скоро начинало смеркаться, я совершенно не знал куда деваться» [9, с. 70-71].
} 
о его собственных поступках, которые он оказался не в состоянии контролировать, так что поступки и их следствия (начала и концы), связанные с обстоятельствами второй дуэли, оказались смазанными. В последнем абзаце, однако, начало и конец четко разделяются: «Таким образом узнал я конец повести, коей начало некогда так поразило меня» [9, с. 74].

Письмо от поверенного с информацией о графе Сильвио получает утром, прощальный обед он дает вечером, а о времени своего отъезда говорит: «еду сегодня в ночь» [9, с. 67]. Важнейший для Сильвио новый этап его жизни начинается в конце суток: аномалии замысла соответствует аномалия времени. Для второй дуэли Сильвио приходит к графу вечером.

Круговорот времени подчеркивает рутину и даже бессмысленность (не)происходящего. На его фоне тем более выделяются ключевые события в жизни Сильвио, в которых, однако, также не обнаруживается смысла.

\section{Судьба рассказчика}

На языке обсуждаемых категорий может быть описана не только жизнь Сильвио, но и жизнь рассказчика. Его судьба военного сложилась таким образом, что он, как и Сильвио, оказался далек от активного участия в военных действиях. Огонь для него проявляет себя через посредство алкоголя употребление пунша, стрельба по бутылке. Рассказывая о своей жизни в деревне, рассказчик выражает опасение превратиться в горького пьяницу. Упражнения Сильвио в стрельбе он также описывает в терминах алкоголя: «Лучший стрелок, которого удалось мне встречать, стрелял каждый день, по крайней мере три раза перед обедом. Это у него было заведено, как рюмка водки» [9, с. 72]. Из этой формулы, неразрывно связывающей стрельбу и алкоголь, можно вывести, что грозящая рассказчику эволюция до крайних пределов алкоголизма соответствует мании Сильвио, связанной с местью и проистекающим отсюда постоянным упражнениям в стрельбе. А само соединение стрельбы и алкоголя - реализация сочетания огня и жидкости.

Рассказчик дважды оказывается вовлечен в круговорот циклического времени. В полку он проводит время в манеже, ездя по кругу. В отставке, в деревне, он проводит время, «разъезжая по работам или обходя новые заведения», причем здесь проявляет себя и суточный цикл: «коль скоро начинало смеркаться, я совершенно не знал куда деваться», [9. С. 70 - 71]. Однако даже такая жизнь захолустного военного, которая для Сильвио была противоположностью насыщенной жизни в гусарах, для рассказчика, напротив, оказывается яркой противоположностью отставки: «я не переставал тихонько воздыхать о прежней моей шумной и беззаботной жизни» [9. С. 70].

\section{Заключение}

Сравнительно небольшое число мотивов и (со)противопоставлений между ними организуют смысловое пространство повести. Сюда, среди рассмотренных в данной работе элементов, относятся противопоставление клинка и пули, холодного и огнестрельного оружия, жара и холода, огня и воды (жидкости), света и тьмы, утра и вечера. На последнее из этих противопоставлений накладывается циклическое движение во времени и пространстве, в котором нет выделенных точек, так что дуальные противопоставления скрадываются. Вся эта система перекрещивающихся мотивов и противопоставлений между отдельными парами (в тех случаях, когда их можно выделить), приобретает экзистенциальное измерение. За этим разнообразием скрывается жизнь, имеющая ложную цель или не имеющая цели вовсе: так и не названное слово «цель» в контексте истории о выстреле обнаруживает свою двусмысленность.

\section{СПИСОК ИСТОЧНИКОВ И ЛИТЕРАТУРЫ}

1. Архангельский А.Н. Герои Пушкина. «Выстрел». URL: http://pushkin-lit.ru/pushkin/articles/arhangelskij-geroipushkina/vystrel.htm

2. Благой Д.Д. Мастерство Пушкина. М., 1955.

3. Заславский О.Б. Двойная структура «Выстрела». Новое литературное обозрение. 1997. № 23. С. $122-131$.

4. Заславский О.Б. Выстрел в структуре «Выстрела» // Новый филологический вестник. 2018. № 44 (1). С. $190-199$.

5. Заславский О. Б. Отложенная дуэль в «Выстреле» как фактор структуры текста // Практики и интерпретации. 2020. Т. 5, № 2. С. 87-103. 
6. Заславский О.Б. Парадокс жертвы в «Выстреле» // Парадоксы русской литературы. СПб., 2001 (Петербургский сборник № 3). С. 117-131.

7. Карасев Л.В. Флейта Гамлета. Очерк онтологической поэтики. М.: Языки славянской культуры, 2009.

8. Лямина Е.Э. Осповат А.Л. Императив неправдоподобия: Как рассказан пушкинский «Выстрел» // Wiener Slavistisches Jahrbuch. 2019. T. 7. C. 61-75.

9. Пушкин А.С. Полное собрание сочинений: в 16 т. М.; Л.: Изд-во АН СССР, 1937-1959. Т. 8, кн. 1. Романы и повести. Путешествия. 1948.

10. Пушкин А.С. Собр. соч.: в 5 т. Т. 4. СПб.: Библиополис, 1994.

11. Славутин Е.И., Пимонов В.И. Структура сюжета. М., Флинта. 2018.

12. Тудоровская Е.А. Время «Повестей Белкина» // Вопросы литературы и фольклора. Воронеж, 1973.

13. Davydov S. "The Shot" by Aleksandr Pushkin and its Trajectories. // J.D. Clayton (Ed.), Issues in Russian literature before 1917: Selected Papers of the Third World Congress for Soviet and East European Studies. Columbus, Ohio: Slavica Publishers, 1989.

14. Shaw T. J. Puskin's «The Shot» // Indiana Slavic Studies. 1963. III. P. 113-129.

Поступила в редакцию 14.06.2020

Заславский Олег Борисович, доктор физико-математических наук, ведущий научный сотрудник

Харьковский национальный университет им. В. Н. Каразина

61022, Украина, г. Харьков, пл. Свободы, 4

E-mail: zaslav@ukr.net

\section{O.B. Zaslavskiy}

ONE MORE TIME ON DOUBLE STRUCTURE OF "THE SHOT" OF A.S. PUSHKIN

DOI: 10.35634/2412-9534-2021-31-2-276-282

We reveal a number of structural elements of "The Shot" overlooked before. Mainly, they are presented by a set of oppositions or realize the motif of doubling directly. This motif is related to confrontation between adversaries and peculiarities of an abnormal duel, including the situation "bullet in bullet". As a result, the life of Silvio appears as a united plot, details of which are expressed in terms of weapon that was exploited by him or remained without application. In particular, this includes the rule of card play in bank in which Silvio was involved. Among artistically relevant oppositions are those between blade and bullet, heat and cold, fire and water, morning and evening. These categories also apply to the count and the narrator. We point to some hidden elements in the brief mentioning the death of Silvio.

Keywords: motif, artistic time, dual oppositions.

\section{REFERENCES}

1. Arhangel'skij A.N. Geroi Pushkina. «Vystrel». [Pushkin's characters. "The Shot”] http://pushkin-lit.ru/pushkin/ articles/arhangelskij-geroi-pushkina/vystrel.htm (In Russian).

2. Blagoj D.D. Masterstvo Pushkina. [Pushkin's workmanship] M., 1955. (In Russian).

3. Zaslavskii O.B. Dvoynaya struktura "Vystrela" [Twofold structure of "The Shot"]. Novoe literaturnoe obozrenie [New literary review], 23, 122-131. (In Russian).

4. Zaslavskii O.B. Vystrel v strukture "Vystrela". Novyj filologicheskij vestnik. 44 (1) 2018. S. 190-199. [A shot in the structure of "The Shot"] (In Russian).

5. Zaslavskii O.B. Otlozhennaja dujel' v «Vystrele» kak faktor struktury teksta. Praktiki i in-terpretacii. 2020. Tom 5, № 2. S. 87-103. [Posponed duel in "The Shot" as a factor of a structure of text] (In Russian).

6. Zaslavskii O.B. Paradoks zhertvy v "Vystrele". // Paradoksy russkoj literatury. Sankt-Peterburg. 2001 (Peterburgskij sbornik № 3). S. 117-131. [Paradox of sacrifice in "The Shot”] (In Russian).

7. Karasev L.V. Fleyta Gamleta. Ocherk ontologicheskoy poetiki [Hamlet's Flute. Essay on Ontological Poetics.] Moscow. 2009. (In Russian).

8. Ljamina E.Je. Ospovat A.L. Imperativ nepravdopodobija: Kak rasskazan pushkinskij «Vystrel» // Wiener Slavistisches Jahrbuch. 2019. T. 7. S. 61-75. [Imperative of unlikeliness: how Pushkin's "The shot" is told] (In Russian).

9. Pushkin A.S. Vystrel. In Pushkin A. S. Polnoe sobranie sochinenij [Complete works]. In 16 vols. Moscow, Leningrad, AS USSR Publ., 1948, vol. 8, book 1. (In Russian).

10. Pushkin, A.S. (1994). Sobraniye sochineniy. V 5 tomakh [Collection of works in 5 volumes] (Vol. 4). St. Petersburg: Bibliopolis. (In Russian).

11. Slavutin E.I., Pimonov V.I. Struktura sjuzheta. [Structure of plot] M., Flinta. 2018. (In Russian). 
12. Tudorovskaja E.A. Vremja «Povestej Belkina» [Time of “Tales of Belkin”] // Voprosy literatury i fol'klora. Voronezh, 1973. (In Russian).

13. Davydov S. (1989). “The Shot” by Aleksandr Pushkin and its Trajectories // J.D. Clayton (Ed.), Issues in Russian literature before 1917: Selected Papers of the Third World Congress for Soviet and East European Studies. Columbus, Ohio: Slavica Publishers. (In English).

14. Shaw T.J. Puskin's «The Shot»// Indiana Slavic Studies. 1963. III. P. 113-129. (In English).

Zaslavskiy O.B., Doctor of Science in Physics and Mathematics, Senior Scientific Fellow Kharkiv V.N. Karazin National University

Svobody sq. 4, Kharkiv, Ukraine, 61022

E-mail: zaslav@ukr.net 